7. Fischer S, Simon AR, Welte T, Hoeper MM, Meyer A, Tessmann R, et al. Bridge to lung transplantation with the novel pumpless interventional lung assist device NovaLung. J Thorac Cardiovasc Surg. 2006;131:719-23.

8. Fischer S, Hoeper MM, Tomaszek S, Simon A, Gottlieb J, Welte T, et al. Bridge to lung transplantation with the extracorporeal membrane ventilator No- valung in the veno-venous mode: the initial Hannover experience. Asaio $J$ 2007;53:168-70.

9. Schmid C, Philipp A, Hilker M, Arlt M, Trabold B, Pfeiffer M, et al. Bridge to lung transplantation through a pulmonary artery to left atrial oxygenator circuit. Ann Thorac Surg. 2008;85:1202-5.

\title{
Direct aortic access through right minithoracotomy for implantation of self-expanding aortic bioprosthetic valves
}

Giuseppe Bruschi, MD, ${ }^{\mathrm{a}}$ Federico De Marco, MD, ${ }^{\mathrm{a}}$ Pasquale Fratto, MD, ${ }^{\mathrm{a}}$ Jacopo Oreglia, MD, ${ }^{\mathrm{a}}$ Paola Colombo, MD, PhD, ${ }^{\mathrm{a}}$ Roberto Paino, MD ${ }^{\mathrm{b}}$ Silvio Klugmann, MD, ${ }^{\mathrm{a}}$ and Luigi Martinelli, MD, ${ }^{\mathrm{a}}$ Milan, Italy

The development of transcatheter aortic valve implantation (TAVI) for the treatment of severe aortic stenosis (AS) offers a viable option for patients at high risk or with contraindications for standard cardiac surgery. ${ }^{1}$ We report our experience of a novel surgical approach using direct aortic access through a right minithoracotomy for implanting a self-expanding aortic valve bioprosthesis (CoreValve, Medtronic-CV Luxembourg S.a.r.l.).

\section{CLINICAL SUMMARY}

Patient 1 is an 83-year-old woman (height, $145 \mathrm{~cm}$; weight, $40 \mathrm{~kg}$; body mass index, $19 \mathrm{~kg} / \mathrm{m}^{2}$ ) with symptomatic severe AS and New York Heart Association class III heart failure. She had a peak transvascular pressure gradient of $130 \mathrm{~mm} \mathrm{Hg}$, an aortic valve area of $0.5 \mathrm{~cm}^{2}$, and an aortic annulus of $18 \mathrm{~mm}$.

Patient 2 is a 60-year-old woman (height, $151 \mathrm{~cm}$; weight, $135 \mathrm{~kg}$; body mass index, $59.2 \mathrm{~kg} / \mathrm{m}^{2}$ ) with symptomatic severe AS, New York Heart Association class III, and severe bronchopneumopathy. The patient had a peak transvascular pressure gradient of $137 \mathrm{~mm} \mathrm{Hg}$ and an aortic valve area of $0.6 \mathrm{~cm}^{2}$.

According to our institutional protocol, the patients were jointly evaluated by a cardiovascular team, and the final decision of eligibility for undergoing TAVI was made. The femoral approach and axillary access were excluded because of

\footnotetext{
From the A De Gasperis Cardiology and Cardiac Surgery Department, ${ }^{\mathrm{a}}$ and Cardiothoracic Anesthesia and Intensive-care, ${ }^{\mathrm{b}}$ Niguarda Ca' Granda Hospital, Milan, Italy. Disclosures: None.

Received for publication Jan 18, 2010; accepted for publication Feb 20, 2010; available ahead of print April 15, 2010.

Address for reprints: Giuseppe Bruschi, MD, A De Gasperis Cardiology \& Cardiac Surgery Department, Niguarda Ca' Granda Hospital, Piazza dell'Ospedale Maggiore 3, 20162 Milan, Italy (E-mail: giuseppe.bruschi@fastwebnet.it).

J Thorac Cardiovasc Surg 2010;140:715-7

0022-5223/\$36.00

Copyright (c) 2010 by The American Association for Thoracic Surgery

doi:10.1016/j.jtcvs.2010.02.030
}

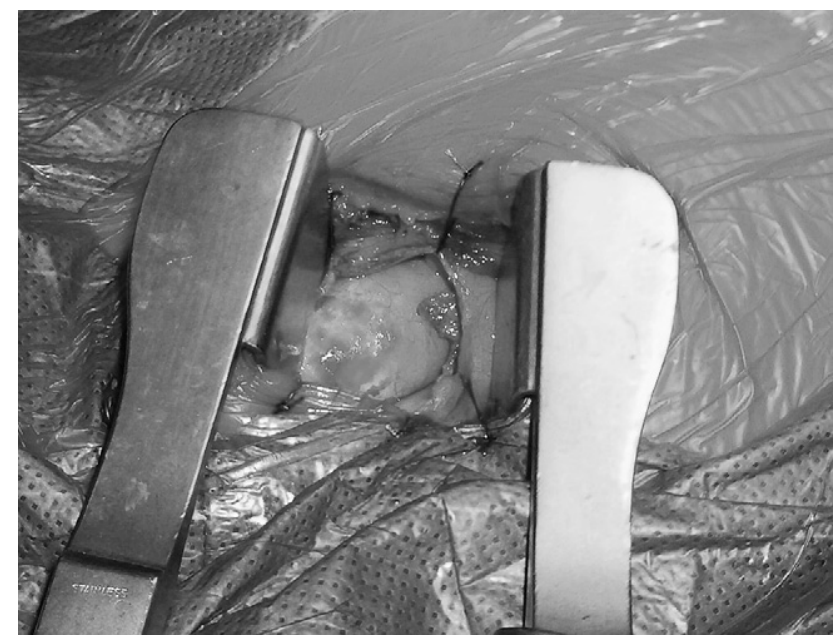

FIGURE 1. Ascending aorta exposure via right minithoracotomy

small vessel size. The transapical approach was deemed to be suboptimal because of a small-sized left ventricle (LV) and extreme LV hypertrophy (patient 1), and the difficulties in the surgical approach and suboptimal angle between the LV and the ascending aorta (patient 2). In these patients, therefore, we opted for the direct exposure of the ascending aorta via a right anterior minithoracotomy. All patients signed informed, written consent. The procedures were performed by the cardiovascular team composed of interventional cardiologists, cardiac surgeons with expertise in hybrid procedures, and cardiac anesthesiologists. The patients were under general anesthesia and mechanical ventilation. A 5.0-cm incision was made at the level of the second right anterior intercostal space with a right internal thoracic artery-sparing procedure. A soft-tissue rectractor and a small rib retractor (patient 2) were used to access the pericardium (Figure 1). A temporary pacing lead was advanced into the right ventricle, and a $6 \mathrm{~F}$ pigtail catheter was inserted for hemodynamic monitoring and landmark aortic angiography. Heparin was administered 


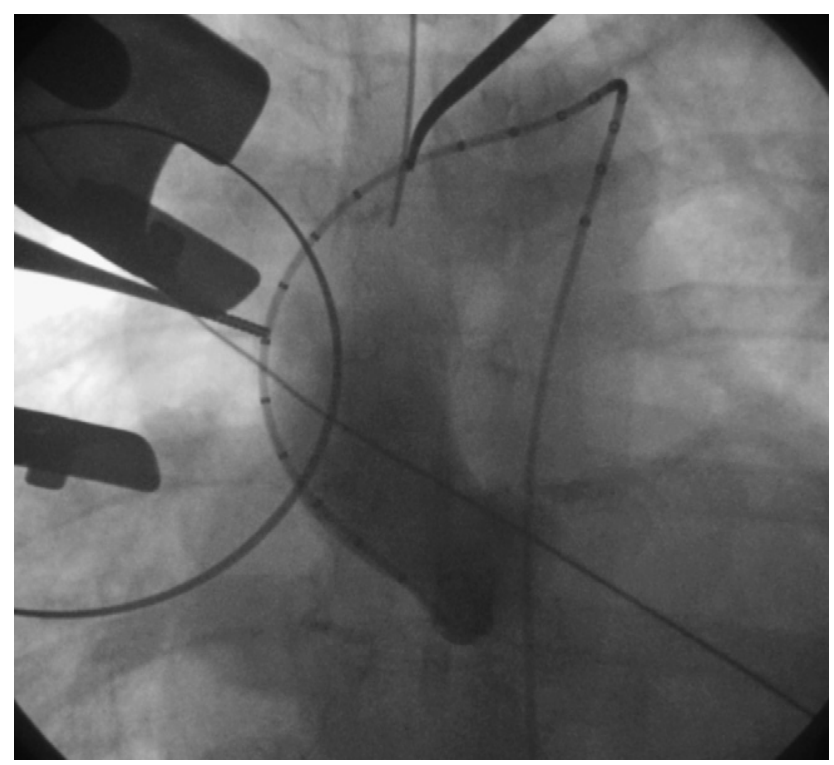

FIGURE 2. Angiographic evaluation of the distance between the aortic annulus and the entry site in the ascending aorta (forceps tips).

as needed to maintain an activated clotting time greater than 250 seconds. Angiography of the basal ascending aorta was performed to measure the distance between the aortic annulus and the entry site in the ascending aorta (Figure 2). Aortic cannulation was performed with the Seldinger technique through a double purse-string suture. A $6 \mathrm{~F}$ sheath was then inserted into the ascending aorta, and a 0.035 straight-tipped guidewire was placed into the LV using a left Amplatz catheter. An 18F introducer was then inserted over a super-stiff guidewire, and the native aortic valve was predilated with a $22-\mathrm{mm}$ Nucleus balloon (NuMED, Inc, Hopkinton, NY). The small 26-mm CoreValve prosthesis was then carefully introduced and retrogradely implanted under angiographic and fluoroscopic guidance in both patients (Figure 3). Immediate improvement in hemodynamic status was observed. Ascending aortic angiography was performed to assess the patency of the coronary arteries and to confirm the absence of paravalvular leaks. Heparin was neutralized with protamine at the end of the procedure, and the thoracotomy was closed. Procedural success was obtained in both cases. After valve deployment, the mean aortic gradient immediately decreased to $5 \mathrm{~mm} \mathrm{Hg}$ or less, with trivial aortic insufficiency. The mean duration of the procedure was 160 minutes. Both patients were extubated in the intensive care unit within the first 24 hours. Postprocedure complete atrioventricular block developed in both subjects, requiring permanent pacemaker implantation. The mean transvalvular aortic pressure gradient at discharge was $10 \mathrm{~mm} \mathrm{Hg}$.

\section{DISCUSSION}

The TAVI procedure may be performed with the transseptal approach, the retrograde approach via the femoral or

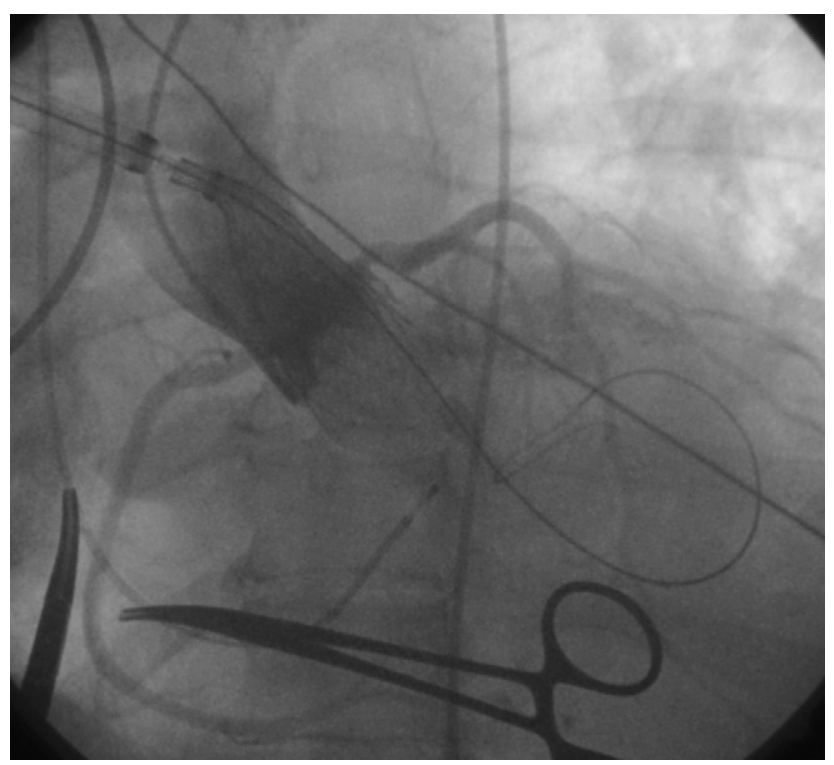

FIGURE 3. CoreValve (Medtronic-CV Luxembourg S.a.r.1.) implantation under angiographic and fluoroscopic guidance.

axillary vessels, or the antegrade transapical approach via a left minithoracotomy. ${ }^{2,3}$ In patients with significant peripheral vascular disease, the transapical approach has been widely and successfully performed by using the EdwardsSAPIEN Valve (Edwards Lifesciences Inc, Irvine, Calif). ${ }^{2}$ Transapical valve implantation has some peculiar technical limitations, as in the case of severe septal hypertrophy, an angled position of the LV outflow tract, calcifications of the apex, and previous thoracotomies. Potential complications include the occurrence of myocardial perforation and mitral or aortic trauma from misdirected stiff catheters, and disruption of the $\mathrm{LV}$ or formation of a false aneurysm in the apical LV cannulation site. ${ }^{4}$ The 2 cases described exemplify the usefulness of a direct access to the ascending aorta via a right anterior minithoracotomy as previously proposed for patients undergoing endovascular aortic stent graft implantation. $^{5}$

\section{CONCLUSIONS}

This technique provides direct access to the aortic annulus, allowing easier manipulation of the device and correct positioning of the CoreValve prosthesis. In addition, our approach can avoid shortcomings that originate from the application of the femoral (dislodging of atherosclerotic material) or transapical approach. In the case of extensive calcification of the ascending aorta, a safe spot on the aorta can be easily identified in most patients. This initial experience suggests that direct transaortic deployment of TAVI is a viable alternative to the standard transapical technique and may overcome the inherent shortcomings associated with the implantation of the self-expanding CoreValve aortic prosthesis. 


\section{References}

1. Yan TD, Cao C, Martens-Nielsen J, Padang R, Ng M, Vallely MP, et al. Transcatheter aortic valve implantation for high-risk patients with severe aortic stenosis: a systematic review. J Thorac Cardiovasc Surg. 2009 Oct 19 [Epub ahead of print].

2. Ye J, Cheung A, Lichtenstein SV, Altwegg LA, Wong DR, Carere RG, et al. Transapical transcatheter aortic valve implantation: 1-year outcome in 26 patients. J Thorac Cardiovasc Surg. 2009;137:167-73.

3. Fraccaro C, Napodano M, Tarantini G, Gasparetto V, Gerosa G, Bianco R, et al. Expanding the eligibility for transcatheter aortic valve implantation: the trans- subclavian retrograde approach using the III Generation CoreValve revalving system. JACC Cardiovasc Interv. 2009;2:828-33.

4. Bleiziffer S, Ruge H, Mazzitelli D, Hutter A, Opitz A, Bauernschmitt R, et al. Survival after transapical and transfemoral aortic valve implantation: talking about two different patient populations. J Thorac Cardiovasc Surg. 2009;138: 1073-80.

5. Vendramin I, Piccoli G, Gasperini Livi U. Right minithoracotomy as an alternative approach for endovascular repair of thoracic aortic aneurysm. J Thorac Cardiovasc Surg. 2007;134:1589-91.

\section{Carinal stabilization technique in severe tracheobronchial malacia after slide tracheoplasty}

\author{
Igor E. Konstantinov, MD, PhD, Melbourne, Australia
}

Pulmonary artery (PA) sling complex is a spectrum of anomalies that commonly include left PA sling, left ligamentum arteriosum, hypoplastic right lung, and severe long-segment tracheal stenosis. ${ }^{1}$ During the last decade, slide tracheoplasty has become the method of choice in repairing severe longsegment tracheal stenosis. ${ }^{2,3}$ However, fewer than 250 children have undergone slide tracheoplasty worldwide. The operative mortality ranges from $5 \%$ to $33 \%{ }^{2,3} \mathrm{PA}$ sling complex and other concomitant cardiovascular anomalies add to the complexity and risk of slide tracheoplasty. Furthermore, severe tracheobronchial malacia often persists after tracheoplasty, resulting in unstable airways. Collapse at the carina results in an inability to deflate both lungs and is lifethreatening. This report describes a simple technique of carinal stabilization that provided effective relief of carinal collapse in severe tracheobronchial malacia after extensive slide tracheoplasty.

\section{CLINICAL SUMMARY}

A 2-month-old boy (height $52 \mathrm{~cm}$, weight $4 \mathrm{~kg}$ ) presented with severe stridor and respiratory failure. PA sling complex was diagnosed (Figure 1, $A-C$ ), consisting of left PA sling, left ligamentum arteriosum, severe long-segmental tracheal stenosis with complete rings ("rat-tail trachea"), bilateral superior venae cavae, and ventricular septal defect. The

\footnotetext{
From the Cardiac Surgery Unit, Royal Children's Hospital, University of Melbourne, Melbourne, Australia.

Disclosures: None.

Received for publication Jan 13, 2010; accepted for publication Feb 20, 2010; available ahead of print April 12, 2010.

Address for reprints: Igor E. Konstantinov, MD, PhD, Royal Children's Hospital, Flemington Road, Parkville, VIC 6009, Australia (E-mail: igor.konstantinov@rch. org.au).

J Thorac Cardiovasc Surg 2010;140:717-9 $0022-5223 / \$ 36.00$

Crown Copyright (C) 2010 Published by Elsevier Inc. on behalf of The American Association for Thoracic Surgery

doi:10.1016/j.jtcvs.2010.02.031
}

complete rings began at the carina and extended to $5 \mathrm{~cm}$ above the carina, preventing insertion of a $3-\mathrm{mm}$ endotracheal tube. The patient was intubated with a $3.5-\mathrm{mm}$ tube positioned right above the narrowing. The patient underwent urgent surgery via a midline sternotomy with cardiopulmonary bypass (CPB) support. Total CPB time was 228 minutes. Aortic crossclamp time was 40 minutes. In surgery, the left ligamentum arteriosum was divided, the left PA was disconnected and reimplanted into the main PA, the ventricular septal defect was closed with autologous pericardial patch, the carina was mobilized, and extensive slide tracheoplasty was performed. Division of both pulmonary ligaments, incision of the posterior pericardial reflection inferiorly, and hilar release contributed significantly to mobilization of the trachea and allowed extensive tension-free slide tracheoplasty (Figure 2, $A, B$ ). However, severe malacia of the carina and both main bronchi caused air-trapping and an inability to deflate the lungs, necessitating patching of the carina with fresh autologous pericardium and externally stabilizing the carina with a ring-enforced, 8mm polytetrafluoroethylene (Gore-Tex; WL Gore and Associates Inc, Flagstaff, Ariz) (Figures $1, D-F$, and $2 C, D$ ) conduit. Both proximal main bronchi and distal trachea were suspended within the external polytetrafluoroethylene (Gore-Tex) frame with the interrupted sutures. The polytetrafluoroethylene (Gore-Tex) graft was split to allow growth of the airways. The trachea and polytetrafluoroethylene (Gore-Tex) were covered with a pericardial flap, as previously described, ${ }^{4}$ to prevent erosion of these structures into the adjacent vessels. The patient was discharged after a short and uneventful postoperative course. However, he was readmitted 2 months after surgery with stridor and granulation tissue at the carina at the site of the autologous pericardial patch. The granulation tissue was removed by rigid bronchoscopy. The patient did not require intubation for this procedure. He was asymptomatic and doing well 3 months after surgery. 